\title{
PENGARUH SUHU INJECTION MOULDING TERHADAP MINIMALISASI SINK MARKS PADA MATERIAL LIMBAH PLASTIK ACRYLONITRILE BUTADIENE STYRENE (ABS)
}

\author{
Dergo Nurhadi*, Helmy Purwanto dan Muhammad Dzulfikar \\ Jurusan Teknik Mesin, Fakultas Teknik, Universitas Wahid Hasyim \\ JL. Menoreh Tengah X/22, Semarang 51585, Indonesia \\ *Email: dergo94@gmail.com
}

\begin{abstract}
Abstrak
Plastik merupakan bahan yang terbentuk dari produk polimerisasi sintetik. acrylonitrile butadiene styrene (ABS) merupakan salah satu jenis plastik. ABS dapat dicetak dengan berbagai proses yaitu cetak injeksi, cetak kompresi, ekstrusi, roto moulding, dan thermoforming. Proses injection moulding merupakan teknik yang sering digunakan dalam pembentukan produk berbahan plastik. Tujuan dari penelitian ini adalah mengetahui dan menganalisis pengaruh temperatur injeksi terhadap cacat sink marks dengan pengujian densitas, uji tarik dan uji struktur makro. Proses injection moulding dilakukan dengan variasi pemanasan menggunakan heater pada temperatur $180^{\circ} \mathrm{C}, 200^{\circ} \mathrm{C}, 220^{\circ} \mathrm{C}, 240^{\circ} \mathrm{C}$ dan $260^{\circ} \mathrm{C}$ kemudian diinjeksikan ke dalam cetakan standar ASTM D638 dengan tekanan konstan injeksi $0,68 \mathrm{~N} / \mathrm{mm}^{2}$. Sink marks adalah cacat produk berupa penyusutan. Faktor yang mempengaruhi sink marks adalah tekanan, suhu, waktu, dan pendinginan. Hasil pembahasan penelitian ini ada pengaruh suhu injection moulding untuk memperoleh minimum sink marks pada uji densitas, uji tarik dan foto makro.
\end{abstract}

Kata kunci : acrylonitrile butadiene styrene, Injection moulding, sink marks

\section{PENDAHULUAN}

Plastik adalah suatu polimer yang mempunyai sifat-sifat unik dan luar biasa. Berdasarkan ketahanan plastik terhadap perubahan suhu, maka plastik dibagi menjadi dua yaitu termoplastik dan thermoset. Thermoplastic adalah jenis plastik yang meleleh pada temperatur tertentu, melekat mengikuti perubahan temperatur, dapat kembali ke bentuk semula atau mengeras bila dinginkan (reversible). Contohnya adalah polyethylene (PE), polypropylene (PP), polyethylene terephthalate (PET), poliviniclorida (PVC), polistirena (PS). Sedangkan thermoset adalah jenis plastik ini tidak dapat mengikuti perubahan suhu (tidak reversible) sehingga bila pengerasan telah terjadi maka bahan tidak dapat dilunakkan kembali (Saifuddin, 2005).

Untuk mengatasi permasalahan limbah plastik dilakukan pemanfaatan produk $N G$ (not good) atau gagal (reject) menjadi bahan baku kembali. (Tiwan, 2008) melakukan penelitian tentang sifat mekanik bahan plastik Acrylonitrile Butadiene Styrene (ABS) daur ulang. Pada penelitian tersebut dapat dijelaskan bahwa campuran bahan ABS daur ulang dari $10 \%$ sampai $50 \%$ berpengaruh terhadap tampilan, nilai kekuatan tarik, nilai regangan, nilai modulus elastisitas, nilai kekuatan impaknya dan nilai kekerasannya. Penambahan campuran bahan tersebut masih dapat diproduksi kembali dari bahan ABS daur ulang.

Acrylonitrile Butadiene Styrene (ABS) merupakan salah satu jenis plastik yang terbentuk dari 3 jenis monomer yaitu Acrylonitrile, Butadiene, dan Styrene. ABS memiliki sifat stabil ketika terkena panas, tahan terhadap bahan kimia, tahan pukul, liat, kaku, dan mudah dibuat berbagai bentuk. Selain itu material plastik ABS dapat dicetak dengan berbagai proses yaitu cetak injeksi, cetak tiup, cetak kompresi, ekstrusi, roto moulding, dan thermoforming (Mujiarto, 2015)

Akan tetapi ABS memiliki kelemahan yaitu cukup mudah tergores, ketahanan terhadap pelarut rendah, processability dan sensitivitas tarikan kurang, serta harganya mahal. Kegunaan plastik ABS dapat diaplikasikan pada bidang otomotif, elektronik, cover mesin dan lain-lain. Selain aplikasi yang luas untuk keperluan mekanika dan teknik, ABS juga mulai digunakan untuk aplikasi elektronik karena beberapa jenis ABS mempunyai ciri khas tahan api (flame retardant), dan memiliki karakteristik elektrik yang baik, tidak berubah pada bentang frekuensi yang luas.

Proses injection moulding adalah salah satu metode pembentukan suatu benda atau produk dari material plastik dengan ukuran dan bentuk tertentu menggunakan alat bantu berupa cetakan atau mould yang diberikan tekanan dan 
perlakuan panas. Injection moulding merupakan salah satu metode yang banyak digunakan karena biaya yang dibutuhkan lebih murah dan dapat memproduksi komponen yang kecil dan rumit (Ajis, 2010).

Metode dasar pembentukan plastik injection moulding bertujuan untuk mendapatkan produk yang sesuai dengan sifat sifat fisik yang diinginkan baik dari sisi luas penampang, ketebalan, desain produk, insert yang panjang, dan toleransi dari sebuah produk yang harus dipenuhi. Material plastik yang digunakan juga merupakan faktor yang sangat berpengaruh dalam pembuatan sebuah produk plastik (Budiyantoro, 2016).

Mesin injection moulding ada dua sumber energi yang menjadi penggerak untuk menjalankan sebuah mesin Injection moulding ini yaitu: sumber udara bertekanan yang berfungsi untuk menekan piston atau plunyer, dan sumber listrik bolak-balik sebagai sumber tenaga untuk bagian pemanas atau heating elements (Firdaus dan Soejono, 2002).

Pengaruh suhu dalam proses injection moulding pada plastik material High Density Poilietilen (HDPE) sangat berperan, karena menyangkut proses plastifikasi dan homogenisasi material (Asror dan Torno, 2003). Proses plastifikasi dan homogenisasi adalah sebuah proses yang berpengaruh pada aliran lelehan plastik (pasta) melt flow rate (MFR) di dalam silinder unit injeksi, yang dipanaskan oleh heater dengan mengatur temperatur yang ditentukan di variasi, sehingga pada penginjeksian menemukan parameter temperatur yang sesuai. Parameter untuk pemrosesan menggunakan tiga tahapan pada material limbah ABS mengacu pada standart ASTM D638, foto struktur makro.

Shrinkage merupakan salah satu cacat yang sering kali didapatkan pada produk plastik. Shrinkage akan timbul apabila terjadi perubahan densitas dari temperatur proses ke temperatur ruangan, cacat shrinkage tidak bisa dihilangkan tetapi dapat dihilangkan atau dikurangi persentasenya dalam sebuah produk. Material plastik dari bahan semi kristal akan lebih besar nilai shrinkage dibandingkan dengan bahan amorphous (Firdaus dan Soejono, 2002).

Adapun tujuan penelitian ini adalah mengetahui dan menganalisis pengaruh temperatur injeksi terhadap cacat sink marks dengan pengujian densitas, uji tarik dan uji struktur makro.

\section{METODE PENELITIAN}

Penelitian ini dilakukan di laboratorium Proses produksi dan laboratorium Material Fakultas Teknik Mesin Universitas Wahid Hasyim Semarang, langkah awal penelitian yang dilakukan adalah mengumpulkan limbah plastik ABS kemudian di cacah dengan menggunakan mesin shredder setelah itu dilakukan proses injection moulding hingga menghasilkan spesimen uji.

Dalam penelitian ini standar yang di gunakan untuk spesimen uji tari adalah ASTM D638, Gambar 1 memperlihatkan dimensi standar ASTM D638.

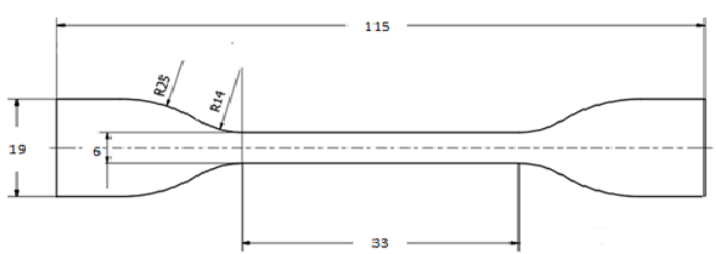

Gambar 1. Dimensi standar ASTM D638

Adapun tahapan dalam penelitian ini dijelaskan pada gambar diagram alir penelitian seperti terlihat pada Gambar 2.

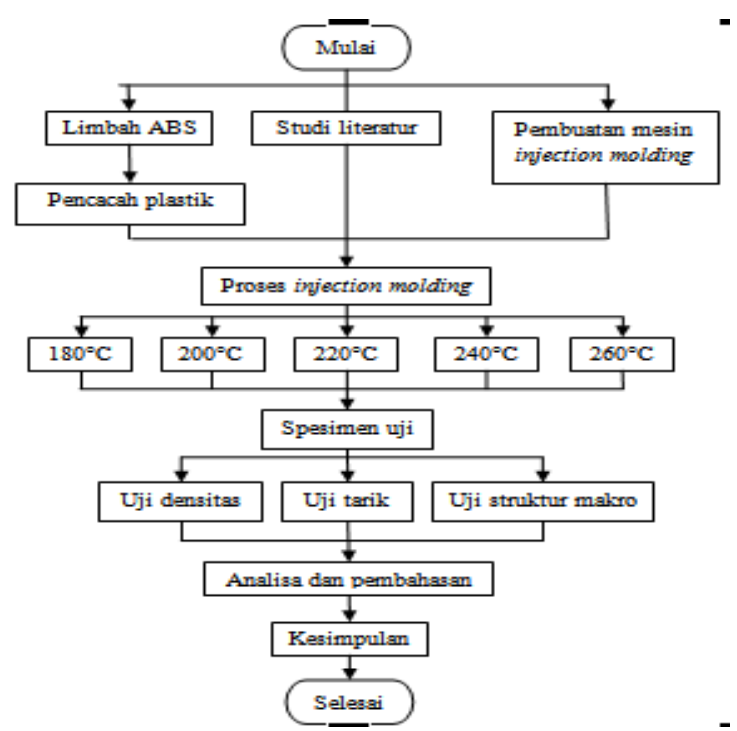

Gambar 2. Diagram alir penelitian

Pertama-tama yang dilakukan adalah mengumpulkan referensi dari penelitian terdahulu dibarengi dengan pembuatan mesin injection moulding dan pengumpulan limbah plastik ABS, setelah itu limbah dicacah menggunakan mesin shredder hasil cacahan langsung diproses ke mesin injection moulding menggunakan variasi temperatur sebesar $180^{\circ} \mathrm{C}$, $200^{\circ} \mathrm{C}, 220^{\circ} \mathrm{C} 240^{\circ} \mathrm{C}$ dan $260^{\circ} \mathrm{C}$ dengan tekanan injeksi sebesar $0,68 \mathrm{~N} / \mathrm{mm}^{2}$. Apabila sudah 
diperoleh spesimen kemudian dilakukan pengujian densitas, uji tarik dan uji struktur makro setelah itu masuk ke tahap pembahasan.

\section{HASIL DAN PEMBAHASAN}

Hasil dari proses injection moulding dengan menggunakan cetakan sesuai standar uji tarik ASTM D638 seperti ditunjukkan pada Gambar 3.

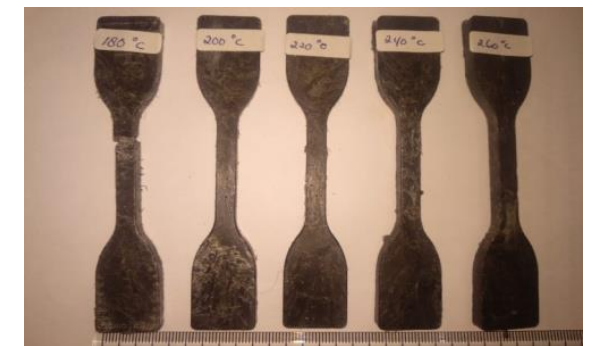

Gambar 3. Spesimen $180^{\circ} \mathrm{C}, 200^{\circ} \mathrm{C}, 2^{\circ 2}{ }^{\circ} \mathrm{C}$, $240^{\circ} \mathrm{C}, \operatorname{dan} 260^{\circ} \mathrm{C}$.

Pengujian yang pertama kali di lakukan adalah uji densitas, hasil pengujian densitas berikut adalah data yang diperoleh seperti ditunjukkan tabel 1

Tabel 1. Data hasil uji densitas

\begin{tabular}{|c|c|c|c|c|c|}
\hline \multicolumn{6}{|c|}{ Densitas $\left(\mathrm{g} / \mathrm{mm}^{2}\right)$} \\
\hline \multicolumn{2}{|c|}{$\begin{array}{c}\text { Temperatur } \\
\left({ }^{\circ} \mathrm{C}\right)\end{array}$} & $\begin{array}{c}\text { Massa } \\
\text { (g) }\end{array}$ & $\begin{array}{l}\text { Volum } \\
\left(\mathrm{cm}^{2}\right)\end{array}$ & $\begin{array}{c}\text { Densitas } \\
\left(\mathrm{g} / \mathrm{cm}^{2}\right)\end{array}$ & $\begin{array}{l}\text { Rata-rata } \\
\left(\mathrm{g} / \mathrm{cm}^{2}\right)\end{array}$ \\
\hline & I & 2,16 & 2,17968 & 0,990971152 & \\
\hline \multirow[t]{3}{*}{180} & II & 2,17 & 2,304344 & 0,941699677 & 0,96 \\
\hline & III & 2,17 & 2,282941 & 0,950528288 & \\
\hline & I & 2,05 & 2,086656 & 0,982433137 & \\
\hline \multirow[t]{3}{*}{200} & II & 2 & 2,126024 & 0,940723153 & 0,96 \\
\hline & II & 2 & 2,120664 & 0,943100840 & \\
\hline & I & 1,98 & 2,260488 & 0,875917059 & \\
\hline \multirow[t]{3}{*}{220} & II & 1,99 & 1,92337 & 1,034642321 & 0,95 \\
\hline & III & 1,8 & 1,88708 & 0,953854633 & \\
\hline & I & 1,7 & 1,895174 & 0,897015261 & \\
\hline \multirow[t]{3}{*}{240} & II & 1,79 & 1,942821 & 0,921340669 & 0,94 \\
\hline & II & 1,89 & 1,90608 & 0,991563838 & \\
\hline & I & 1,79 & 2,082795 & 0,859422075 & \\
\hline \multirow[t]{2}{*}{260} & II & 1,77 & 1,875072 & 0,943963752 & 0,93 \\
\hline & II & 1,8 & 1,8411 & 0,977676389 & \\
\hline
\end{tabular}

Dari hasil pengujian densitas diperoleh hasil sebagai berikut: pada temperatur $180^{\circ} \mathrm{C}$ adalah $0,96 \mathrm{~g} / \mathrm{cm}^{3}$. Kemudian pada temperatur $200^{\circ} \mathrm{C}$ meningkat menjadi $0,96 \mathrm{~g} / \mathrm{cm}^{3}$ dan pada temperatur $220^{\circ} \mathrm{C}$ kembali meningkat menjadi $0,95 \mathrm{~g} / \mathrm{cm}^{3}$. Pada temperatur $240^{\circ} \mathrm{C}$ menjadi $0,94 \mathrm{~g} / \mathrm{cm}^{3}$ dan terakhir pada temperatur $260^{\circ} \mathrm{C}$ kembali meningkat menjadi $0,93 \mathrm{~g} / \mathrm{cm}^{3}$.

Pada gambar 4 temperatur tinggi densitas menjadi rendah dan pada temperatur terendah densitasnya menjadi tinggi, hal ini disebabkan karena pada saat temperatur rendah spesimen tidak mengalami sink marks dan seiring bertambahnya temperatur karena pada material limbah plastik ABS pada temperatur rendah $\left(180^{\circ} \mathrm{C}-200^{\circ} \mathrm{C}\right)$ material tidak mencair merata sehingga cacat sink marks tidak ditemukan, akan tetapi permukaan spesimen kasar belum meleleh sempurna dan temperatur yang terlalu tinggi mengakibatkan penyusutan sehingga menyebabkan adanya cacat sink marks.

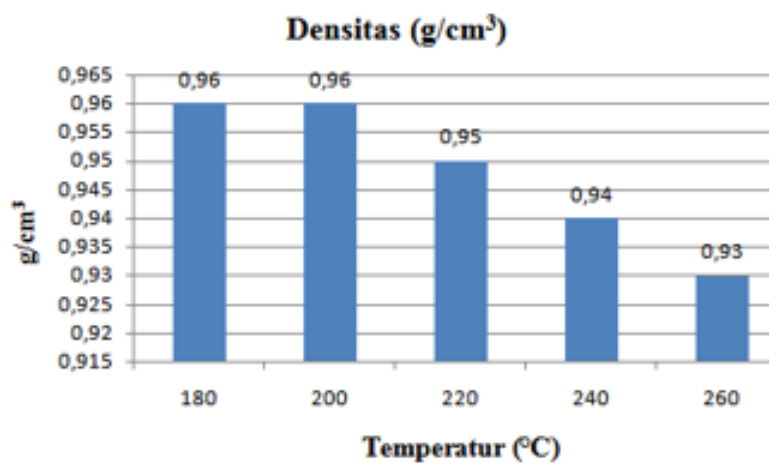

Gambar 4. Grafik hasil uji densitas

Pemilihan temperatur yang tepat dilakukan untuk mengurangi cacat sink marks, untuk material limbah ABS adalah $220^{\circ} \mathrm{C}$. Cacat sink marks mempengaruhi uji densitas, karena spesimen dengan temperatur tinggi massa spesimen menjadi rendah ditunjukkan pada gambar 5 .

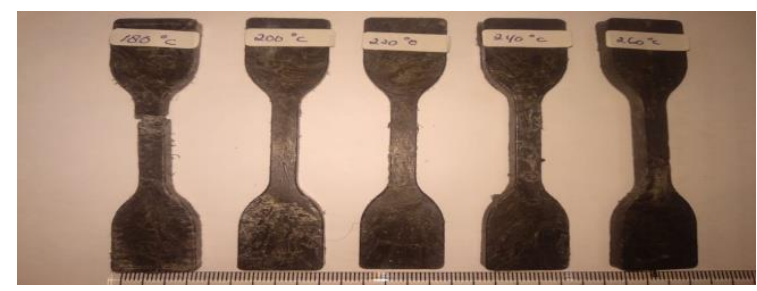

Gambar 5. Cacat sink marks

Pengujian selanjutnya adalah uji tarik, berikut adalah data hasil uji tarik. seperti ditunjukkan tabel 2 dan tabel 3.

Tabel 2. Yield stress uji Tarik

\begin{tabular}{|c|c|c|c|c|}
\hline \multirow{2}{*}{$\begin{array}{l}\text { Temp } \\
\text { (oC) }\end{array}$} & \multicolumn{3}{|c|}{ Yield stress (Kgf $\mathrm{mm} 2)$} & \multirow{2}{*}{$\begin{array}{l}\text { Rata-rata } \\
(\mathrm{MPa})\end{array}$} \\
\hline & I & II & III & \\
\hline 180 & - & 164,060 & 166,100 & 165 \\
\hline 200 & 164,926 & 166,784 & 170,168 & 167 \\
\hline 220 & 169,549 & 172,590 & 172,154 & 171 \\
\hline 240 & 175,190 & 173,148 & 175,373 & 175 \\
\hline 260 & 176,853 & 176,379 & 175,742 & 176 \\
\hline
\end{tabular}


Tabel 3. Maximum stress uji tarik

\begin{tabular}{ccccc}
\hline \multirow{2}{*}{ Temp } & \multicolumn{3}{c}{ Max. stress (Kgfmm2) } & Rata-rata \\
\cline { 2 - 4 } (oC) & I & II & III & (MPa) \\
\hline 180 & - & 174,250 & 177,760 & 176 \\
200 & 182,847 & 183,643 & 182,269 & 183 \\
220 & 186,547 & 186,489 & 183,937 & 186 \\
240 & 189,771 & 182,660 & 185,502 & 186 \\
260 & 186,152 & 191,788 & 180,950 & 186 \\
\hline
\end{tabular}

Yield stress pada temperatur $180^{\circ} \mathrm{C}$ adalah 165 Mpa kemudian pada temperatur $200^{\circ} \mathrm{C}$ meningkat menjadi 167 Mpa dan pada temperatur $220^{\circ} \mathrm{C}$ meningkat kembali menjadi $171 \mathrm{Mpa}$ kemudian pada temperatur $240^{\circ} \mathrm{C}$ terus meningkat menjadi 175 Mpa dan pada temperatur $260^{\circ} \mathrm{C}$ meningkat yaitu $176 \mathrm{Mpa}$.

Maximum stress pada temperatur $180^{\circ} \mathrm{C}$ adalah $176 \mathrm{Mpa}$ kemudian pada temperatur $200^{\circ} \mathrm{C}$ menurun menjadi $183 \mathrm{Mpa}$ dan pada temperatur $220^{\circ} \mathrm{C}$ masih stabil $186 \mathrm{Mpa}$ kemudian pada temperatur $240^{\circ} \mathrm{C}$ masih stabil menjadi $186 \mathrm{Mpa}$ dan pada temperatur $260^{\circ} \mathrm{C}$ stabil yaitu 186 Mpa.

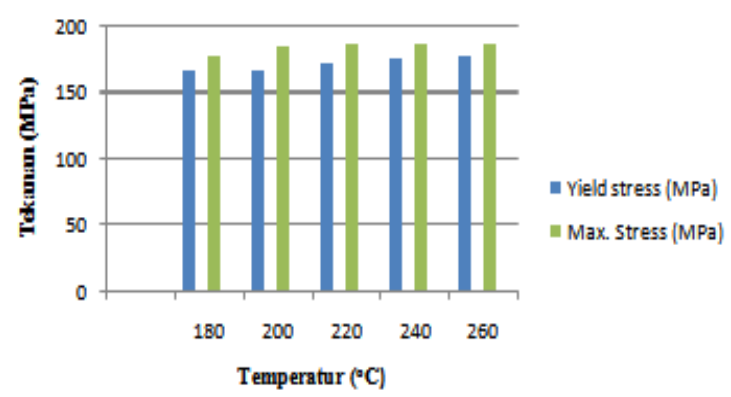

Gambar 6. Grafik Yield stress dan max. stress

Pada gambar 6 dapat dilihat semakin temperatur tinggi akan mempengaruhi Yield stress dan max stress. Penelitian ini sama halnya, yang dilaporkan oleh Asror (2003) perubahan temperatur pada proses injection moulding terhadap material plastik daur ulang berpengaruh signifikan dengan hasil regangan produk tersebut. Hal ini terjadi karena proses pemanasan terus - menerus dan cenderung getas (brittle).

Pengujian elongation uji tarik dapat dilihat data yang diperoleh seperti ditunjukkan tabel 4.
Tabel 4. Elongation uji tarik

\begin{tabular}{|c|c|c|c|c|}
\hline \multirow{2}{*}{$\begin{array}{l}\text { Teap } \\
(0 C)\end{array}$} & \multicolumn{3}{|c|}{ Elongation (Rff $\mathrm{Rm}$ ) } & \multirow{2}{*}{$\begin{array}{l}\text { Ratara } \\
\%\end{array}$} \\
\hline & 1 & II & III & \\
\hline 180 & - & 8,674 & 9,015 & 9 \\
\hline 200 & 13,47 & 12,24 & 11,742 & 13 \\
\hline 220 & 15,000 & 13,258 & 13,485 & 14 \\
\hline 240 & 12424 & 13.333 & 9.42 & 11 \\
\hline 260 & 8,409 & 10,758 & 7,614 & 9 \\
\hline
\end{tabular}

Rata-rata regangan pada $180^{\circ} \mathrm{C}$ adalah $9 \%$ kemudian pada temperatur $200^{\circ} \mathrm{C}$ meningkat menjadi $13 \%$ dan pada temperatur $220^{\circ} \mathrm{C}$ terus meningkat kembali menjadi $14 \%$, akan tetapi pada temperatur, regangan pada temperatur $240^{\circ} \mathrm{C}$ menurun menjadi $11 \%$ pada temperatur $260^{\circ} \mathrm{C}$ sedikit menurun menjadi $9 \%$. Grafik ratarata regangan elongation ditunjukkan pada gambar 7.

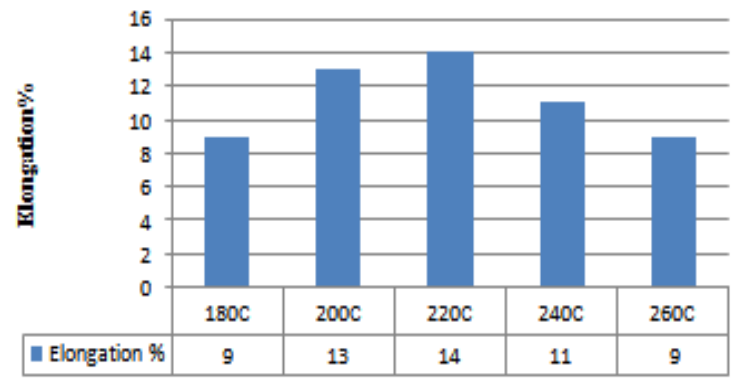

Gambar 7. Grafik Elongation

Rata-rata hasil regangan menunjukkan persentase peningkatan di setiap pertambahan temperatur, akan tetapi pada temperatur $240^{\circ} \mathrm{C}$ menunjukkan regangan menurun hingga temperatur $260^{\circ} \mathrm{C}$, hal ini disebabkan karena pada temperatur yang terlalu tinggi mengakibatkan spesimen uji hasil injection moulding mengalami pengkristalan sehingga spesimen menjadi getas.

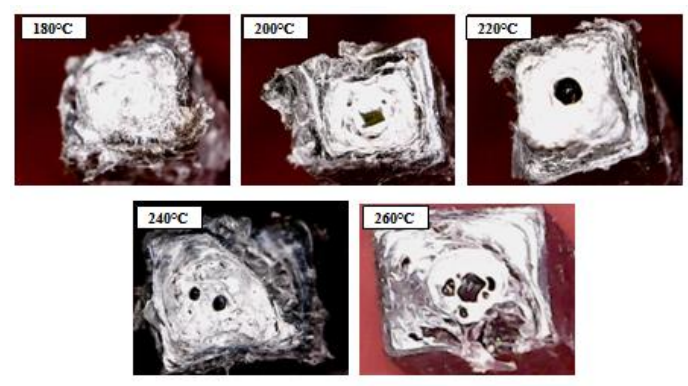

Gambar 8. Foto makro patahan uji tarik 
Pengujian yang terakhir adalah uji foto makro, berikut adalah hasil foto makro dari temperatur $180^{\circ} \mathrm{C}, 200^{\circ} \mathrm{C}, 220^{\circ} \mathrm{C}, 240^{\circ} \mathrm{C}$ dan $260^{\circ} \mathrm{C}$. Ditunjukkan pada gambar 8. Secara umum rata-rata hasil foto makro patah uji tarik pada proses injection moulding dengan temperatur $180^{\circ} \mathrm{C}, 200^{\circ} \mathrm{C}, 220^{\circ} \mathrm{C}, 240^{\circ} \mathrm{C}$, dan $260^{\circ} \mathrm{C}$ pada temperatur $180^{\circ} \mathrm{C}$ mengalami patahan serabut, mulai temperatur $200^{\circ} \mathrm{C}$, $220^{\circ} \mathrm{C}, 240^{\circ} \mathrm{C}$, dan $260^{\circ} \mathrm{C}$ mempunyai patahan getas dan berlubang dibagikan tengahnya, hal ini terjadi karena bahan yang terbuat dari limbah plastik ABS mengalami material limbah plastik ABS masih belum meleleh merata, sehingga masih banyak ditemukan permukaan berwarna putih. Adapun titik pusat patahan tidak terjadi di tengah, melainkan agak ke ujung. Pada gambar IV.18 menunjukkan patahan getas terjadi didaerah tengah spesimen, tetapi pada pusat titik tengah menunjukkan adanya lubang yang cukup besar disebabkan temperatur terlalu tinggi material lebih mencair daripada temperatur rendah sehingga pada saat material diinjeksi udara masuk pada bagian tengah spesimen dan menyebabkan cacat berlubang di tengah spesimen.

\section{KESIMPULAN}

Berdasarkan hasil penelitian tentang analisis pengaruh temperatur daur ulang terhadap sifat mekanis bahan plastik limbah Acrylonitrile Butadiene Styrene (ABS), maka dapat disimpulkan sebagai berikut:

1. Hasil pada pengujian densitas temperatur tinggi densitas spesimen menjadi tinggi dan pada temperatur terendah densitasnya menjadi rendah, hal ini disebabkan karena pada saat temperatur rendah spesimen tidak mengalami sink marks dan seiring bertambahnya temperatur maka semakin sering ditemukan sink marks.

2. Secara umum rata-rata yield stress dan Maximum stress meningkat dengan semakin tingginya temperatur injection moulding. Tingginya temperatur menyebabkan spesimen menjadi getas dan cacat. Hasil temperatur yang tepat pada mesin injection moulding Unwahas bahan material limbah plastik $\mathrm{ABS}$ adalah temperatur $220^{\circ} \mathrm{C}$.

3. Hasil foto makro memiliki cacat rongga pada tengah spesimen berlubang di bagian tengahnya, hal ini terjadi karena bahan yang terbuat dari limbah plastik ABS mengalami pencacahan yang kurang halus sehingga pada saat mesin injeksi di tekan masih ada udara yang terjebak disela-sela bahan sehingga menghasilkan rongga, akan tetapi seiring bertambahnya temperatur injeksi lubang tersebut akan semakin menyusut. Pada temperatur $180^{\circ} \mathrm{C}$ bahan limbah plastik ABS tidak dapat mencair dengan sempurna dan pada temperatur $260^{\circ} \mathrm{C}$ baru bisa mencair dengan sempurna.

\section{SARAN}

Adapun saran-saran yang membangun untuk penelitian selanjutnya antara lain sebagai berikut:

1. Penelitian selanjutnya diharapkan ada uji Melt Flow Index (MFI) berpengaruh terhadap sifat mekanis yaitu pada ketahanan benturan dan kekerasan suatu produk.

2. Perlunya alat injeksi dengan membuat tekanan pada mesin injection moulding menggunakan pneumatika atau hidrolik sehingga tekanan lebih terukur secara akurat dan yang optimal.

\section{DAFTAR PUSTAKA}

Ajis. 2010. Proses pembuatan produk plastik dengan system injection molding. http://ajisandfriends.blogspot.co.id. Diakses pada 22 Februari 2019, Pukul 20.00 WIB.

Asror, M. F., dan Torno, H. S. S. 203.Pengaruh suhu proses dan tekanan injection moulding terhadap kekuatan benturan dan kekerasan pada material High density polyethylene. Jurnal Prosiding symposium nasional polimer IV Sentra Teknologi Polimer (STP)-BPPT, 188-192.

ASTM D 638 - 14 Standart Test Method for Tensile Properties of Plastics. Philadelphia, PA : American Society for Testing Materials.

Budiyantoro, C. 2016. Teknologi Plastik. Perkuliahan Program Studi Teknik Mesin Universitas Muhammadiyah Yogyakarta 
Mujiarto, I. (2005). Sifat dan Karakteristik Material Plastik dan Bahan Aditif. Traksi. Vol. 3. No. 2, Desember 2005.

Saifuddin. (2005). Pembuatan Gelas dengan Bahan Polypropylene Menggunakan Cetakan Plastik. Jurnal Polimesin Volume 16, Nomor 2, Agustus 2018.

Firdaus dan Soejono T., (2002). Studi Eksperimental Pengaruh Parameter Proses Pencetakan Bahan Plastik Terhadap Cacat Penyusutan (Shrinkage) Pada Benda Cetak Pnuematics Holder. Jurnal Teknik Mesin, 4(2): 75-85. 